\title{
CDISC SDTM Lead Abnormality Terminology
}

National Cancer Institute

\section{Source}

National Cancer Institute. CDISC SDTM Lead Abnormality Terminology. NCI Thesaurus.

Code C101862.

Terminology associated with the lead abnormality codelist of the Clinical Data

Interchange Standards Consortium (CDISC) Study Data Tabulation Model (SDT M). 